\title{
Molecular Mapping of Hydrogen Sulfide Targets in Normal Human Keratinocytes
}

\author{
Olivia Gross-Amat ${ }^{1,2,3, *} \mathbb{C}^{-}$, Marine Guillen ${ }^{1}$, Jean-Pascal Gimeno ${ }^{4} \mathbb{C}^{-}$, Michel Salzet ${ }^{4}{ }^{(}$, \\ Nicolas Lebonvallet $^{5}$, Laurent Misery ${ }^{5,6}\left(\mathbb{D}\right.$, Céline Auxenfans ${ }^{2,7,+}+{ }^{\circ}$ and Serge Nataf ${ }^{1,2,3, \dagger}$ \\ 1 Lyon-Est School of Medicine, University Claude Bernard Lyon-1, 69100 Villeurbanne, France; \\ marine.guillen@univ-lyon1.fr (M.G.); serge.nataf@inserm.fr (S.N.) \\ 2 Bank of Tissues and Cells, Lyon University Hospital (Hospices Civils de Lyon), 69003 Lyon, France; \\ celine.auxenfans@chu-lyon.fr \\ 3 CarMeN Laboratory, INSERM U1060, INRA U1397, INSA de Lyon, 69600 Oullins, France \\ 4 Inserm, CHRU Lille, U-1192-Laboratoire Protéomique, Réponse Inflammatoire et Spectrométrie de \\ Masse-PRISM, University of Lille, F-59000 Lille, France; jean-pascal.gimeno@univ-lille.fr (J.-P.G.); \\ michel.salzet@univ-lille.fr (M.S.) \\ 5 Laboratory of Epithelial-Neural Interactions, University of Brest, LIEN, 29200 Brest, France; \\ nicolas.lebonvallet@univ-brest.fr (N.L.); laurent.misery@chu-brest.fr (L.M.) \\ 6 Department of dermatology, Brest University Hospital (CHU de Brest), 29200 Brest, France \\ 7 Tissue Biology and Therapeutic Engineering Laboratory, UMR 5305, 69007 Lyon, France \\ * Correspondence: olivia.gross.amat@free.fr \\ + These authors contributed equally to this work.
}

Received: 1 May 2020; Accepted: 26 June 2020; Published: 30 June 2020

\begin{abstract}
Although sulfur-rich thermal waters have ancestrally been used in the context of dermatological conditions, a global mapping of the molecular effects exerted by $\mathrm{H}_{2} \mathrm{~S}$ on human keratinocytes is still lacking. To fill this knowledge gap, we subjected cultured human keratinocytes to distinct amounts of the non-gaseous hydrogen sulfur donor $\mathrm{NaHS}$. We first checked that $\mathrm{H}_{2} \mathrm{~S}$ accumulated in the cytoplasm of keratinocytes under our experimental conditions andused a combination of proteomics, genomics and biochemical approaches to unravel functionally relevant $\mathrm{H}_{2} \mathrm{~S}$ targets in human keratinocytes. We found that the identified targets fall into two main categories: (i) the oxidative stress response molecules superoxide dismutase 2 (SOD2), NAD(P)H quinone dehydrogenase 1 (NQO1) and culin 3 (CUL3) and (ii) the chemokines interleukin-8 (IL-8) and CXCL2. Interestingly, NaHS also stimulated the caspase- 1 inflammasome pathway, leading to increased secretion of the pro-inflammatory molecule interleukin-18 (IL-18). Interestingly, the secretion of interleukin-1 beta (IL-1 $\beta$ ) was only modestly impacted by NaHS exposure despite a significant accumulation of IL-1 $\beta$ pro-form. Finally, we observed that NaHS significantly hampered the growth of human keratinocyte progenitors and stem cells cultured under clonogenic conditions or as epidermal cell sheets. We conclude that $\mathrm{H}_{2} \mathrm{~S}$ exerts specific molecular effects on normal human keratinocytes.
\end{abstract}

Keywords: human keratinocyte; $\mathrm{H}_{2} \mathrm{~S}$; RNAseq; proteomics

\section{Introduction}

Sulfur-rich thermal waters are an ancestral dermatological therapy which nowadays is used as an adjunct treatment for psoriasis and atopic dermatitis [1-4] but also chronic skin wounds [4,5]. Hydrogen sulfide $\left(\mathrm{H}_{2} \mathrm{~S}\right)$, the main bioactive component specific to sulfur-rich thermal waters, belongs to the small family of physiological gaseous transmitters, which also comprises nitric oxide (NO) and carbon monoxide (CO). Similarly to $\mathrm{NO}$ and $\mathrm{CO}, \mathrm{H}_{2} \mathrm{~S}$ is endogenously produced and exerts potent signaling effects, but exhibits a short half-life and a rapid decrease in its concentration at the site of production 
or application. Such a volatility renders the use of $\mathrm{H}_{2} \mathrm{~S}$ difficult under in vitroor in vivo experimental conditions. As a consequence, the non-gaseous hydrogen sulfur donor NaHS is frequently preferred for research purposes. In order to mimic the impact of sulfur-rich spa waters on skin cells, previous works thus assessed the effects of NaHS on the proliferation, differentiation, adhesion properties and cytokine profile of cultured human keratinocytes [6-10]. Under these experimental conditions, NaHS was notably reported to inhibit the synthesis of anti-inflammatory molecules such as IL- 8 and IL- $1 \beta$, which provided support for the use of sulfur-rich thermal waters for the treatment of psoriasis [7,9]. However, as such findings were obtained from transformed keratinocyte cell lines, their physiological relevance remains to be confirmed in primary cultures of keratinocytes. Moreover, none of the above-mentioned works used systems biology approaches to assess, other than a priori, the global impact of NaHS on human keratinocytes. Hence, a systematic molecular mapping of the effects exerted by NaHS on human primary cultures of keratinocytes is still missing. To fill this knowledge gap, we performed here a pan-genomics and pan-proteomics analysis of cultured human keratinocytes exposed to NaHS. Our results show that NaHS inhibits the proliferation of human keratinocyte progenitors and stem cells, stimulates their secretion of specific pro-inflammatory cytokines and promotes the synthesis of molecules involved in antioxidative response. These findings provide insights into the molecular effects exerted by sulfur-rich spa waters on skin cells and point to the potential role of $\mathrm{H}_{2} \mathrm{~S}$ as a gaseous regulator of epidermal cell homeostasis.

\section{Results}

\subsection{NaHS Induces a Rapid and Transient Increase in $\mathrm{H}_{2} \mathrm{~S}$ in Human Keratinocyte Cultures}

To assess the actual impact of NaHS on the generation of $\mathrm{H}_{2} \mathrm{~S}$ in our experimental conditions, we first measured $\mathrm{H}_{2} \mathrm{~S}$ amounts in the supernatant of control vs. NaHS-treated cultures of human keratinocytes. We found that NaHS added to the culture media at a concentration of $0.25 \mathrm{mM}$ induced a quick rise in $\mathrm{H}_{2} \mathrm{~S}$, irrespective of the presence or absence of cultured keratinocytes (Figure 1a). As a return to baseline levels was observed $1 \mathrm{~h}$ after NaHS exposure (Figure 1a), these results demonstrate that $\mathrm{NaHS}$ exerts rapid and transient effects on $\mathrm{H}_{2} \mathrm{~S}$ amounts measured in the culture media. In parallel experiments, we also sought to determine whether, as a consequence of an $\mathrm{H}_{2} \mathrm{~S}$ rise in the culture medium, an intracellular increase in $\mathrm{H}_{2} \mathrm{~S}$ could be observed in the cytoplasm of cultured human keratinocytes. The use of a fluorescent $\mathrm{H}_{2} \mathrm{~S}$ probe allowed us to demonstrate that NaHS-treated keratinocytes exhibited an intracytoplasmic accumulation of $\mathrm{H}_{2} \mathrm{~S}$, which could be observed $1 \mathrm{~h}$ following NaHS exposure (Figure $1 \mathrm{~b}$ and Data Supplement Figure S1). Interestingly, such an effect appeared to be more pronounced when higher concentrations of NaHS were applied (Figure 1b).

\subsection{NaHS Impairs the Growth of Human Keratinocyte Progenitors and Stem Cells}

To assess the impact of NaHS on the growth of keratinocyte progenitors and stem cells, we performed a keratinocyte clonogenic assay (CFU) and measured the effects of NaHS $(0.02 \mathrm{mM}$ or $0.25 \mathrm{mM})$ on both the number and size of colonies. While the number of clones remained unchanged under NaHS treatment (Figure 2a,b), we observed that the clones exhibited smaller sizes (Figure 2a). Accordingly, the counts of harvested cells obtained 10-14 days post-treatment were nearly $80 \%$ lower in cultures treated with $0.25 \mathrm{mM}$ NaHS as compared to controls (Figure 2c). Such an effect was not observed when $0.02 \mathrm{mM}$ NaHS was applied. Similarly, in cultures of human epithelial cell sheets, which are composed of more than 90\% CD49f-positive keratinocyte progenitors [11,12] (Data Supplement, Figure S2 and Table S1), total cell counts were significantly lower in NaHS-treated cultures as compared to controls (Figure 2d). However, such a growth-limiting effect was less pronounced under these experimental conditions and reached only $30 \%$ in NaHS-treated as compared to control cultures. Again, NaHS applied at concentrations below $0.25 \mathrm{mM}$ had no impact on the growth of keratinocyte progenitors. Of note, irrespective of the tested NaHS concentrations (from 0.0025 to $4 \mathrm{mM}$ ), we did 
not observe any impact on keratinocyte cell viability as assessed by trypan blue coloration or MTT (3-(4,5-dimethylthiazol-2-yl)-2,5-diphenyltetrazolium bromide) assay (Data Supplement, Figure S3).

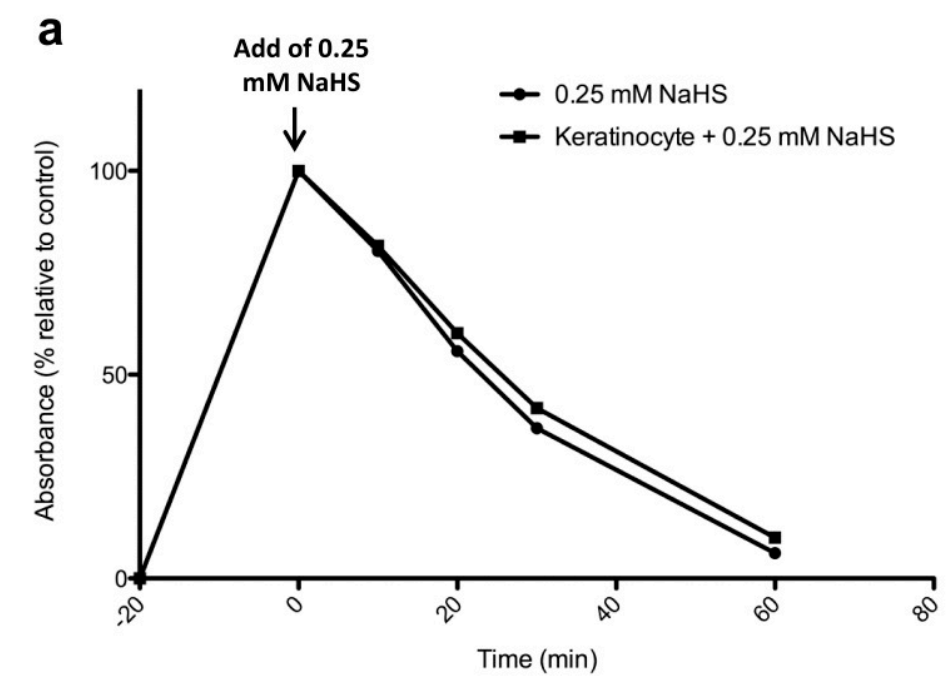

b

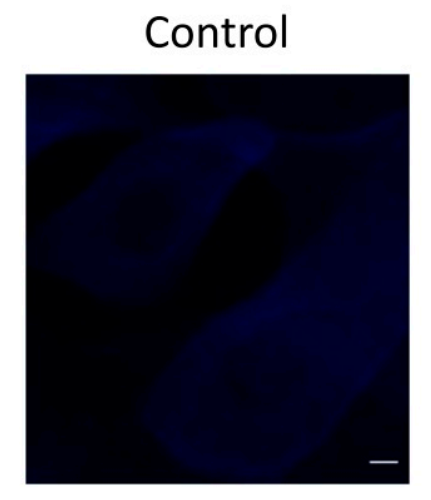

\section{$0.25 \mathrm{mM} \mathrm{NaHS}$}

\section{$2 \mathrm{mM}$ NaHS}
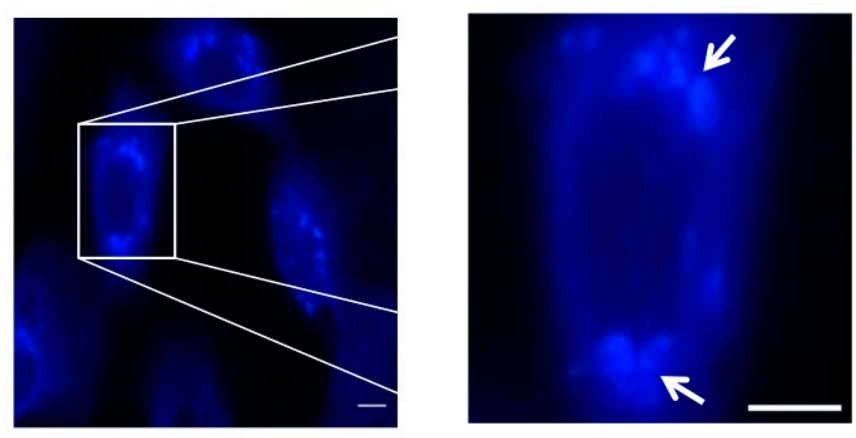

Figure 1. NaHS induces the extracellular and intracellular accumulation of $\mathrm{H}_{2} \mathrm{~S}$ in human keratinocyte cultures. (a) Kinetics of $\mathrm{H}_{2} \mathrm{~S}$ accumulation in keratinocyte culture medium following addition of $0.25 \mathrm{mM}$ NaHS in the presence or absence of cultured keratinocytes. (b) The use of a fluorescent $\mathrm{H}_{2} \mathrm{~S}$ probe allowed detection of $\mathrm{H}_{2} \mathrm{~S}$ accumulation (arrows) in the cytoplasm of cultured keratinocytes stimulated with NaHS at a concentration of 0.25 or $2 \mathrm{mM}$. Results are representative of three to five experiments. Scale bar: $0.01 \mathrm{~mm}$. 
a
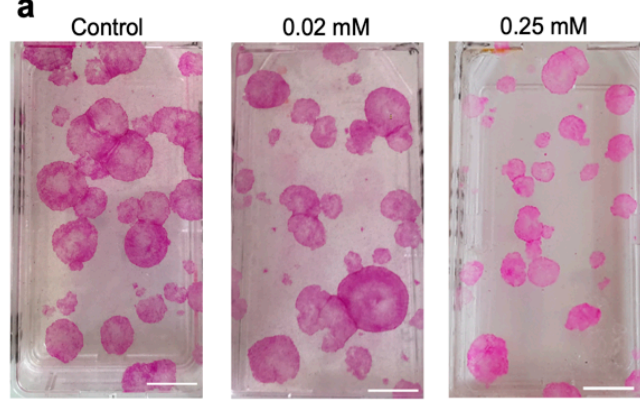

C

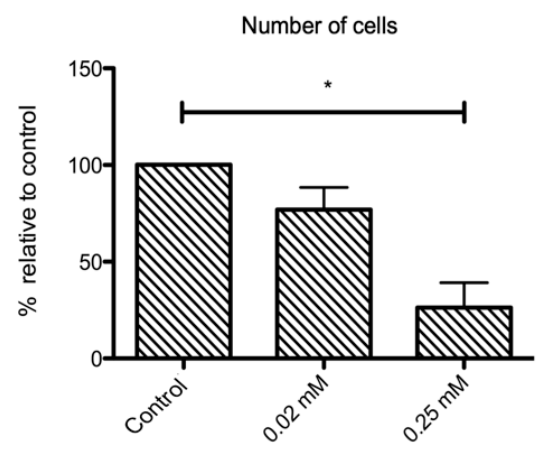

b
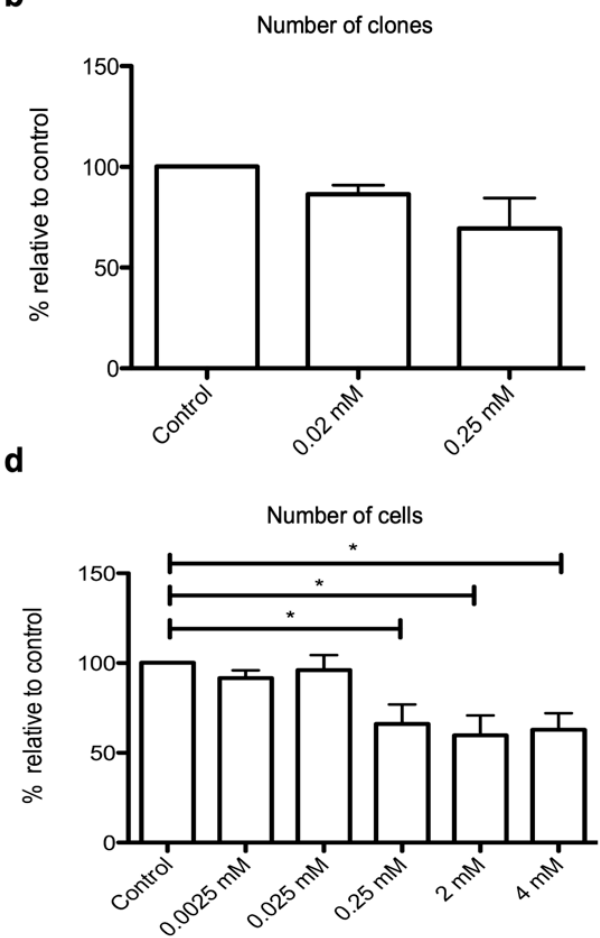

Figure 2. NaHS impairs the growth of human epidermal stem cells and epidermal cell sheets. $(\mathbf{a}-\mathbf{c})$ Human keratinocytes cultured under clonogenic conditions were stimulated every other day with NaHS at 0.02 or $0.25 \mathrm{mM}$ concentrations during 12 days. Cells were then fixed and stained with hematein-eosin, allowing colonies of keratinocyte stem or progenitor cells to be manually counted. Keratinocyte cultures generated in parallel under strictly identical conditions were trypsinized, and living cells were numerated following trypan blue staining. Four keratinocyte cultures deriving from four distinct donors were used in these experiments. (a) Representative images of grown colonies obtained under control condition (upper panel) or under NaHS stimulation at $0.02 \mathrm{mM}$ concentration (middle panel) or $0.25 \mathrm{mM}$ concentration (lower panel). Images show that, as compared to control untreated cells or cells treated with $0.02 \mathrm{mM} \mathrm{NaHS}$, colonies are of lower size in cells treated with $0.25 \mathrm{mM}$ NaHS (b) Irrespective of NaHS concentration, the total number of colonies remains unchanged in NaHS-treated cells as compared to control cells. (c) However, the total number of harvested living cells is significantly lower in cultures treated with $0.25 \mathrm{mM}$ NaHS as compared to control untreated cultures. (d) The effects of NaHS on the cellular density of epidermal cell sheets were assessed after $24 \mathrm{~h}$ treatment with $\mathrm{NaHS}$ at concentrations ranging from $0.0025 \mathrm{mM}$ to $4 \mathrm{mM}$. Experiments were performed on cells obtained from six distinct donors. Results are expressed as percentages relative to control conditions. Statistical significance of paired comparisons was assessed with the Wilcoxon test. *: $p<0.05$. Scale bar: $1 \mathrm{~cm}$.

\subsection{NaHS Stimulates the Synthesis of Superoxide Dismutase 2 (SOD2) by Cultured Human Keratinocytes}

We used liquid chromatography-mass spectrometry (LC-MS) to perform a pan-proteomic analysis of the effects exerted by $0.25 \mathrm{mM}$ NaHS on human epidermal cell sheets. It should be noticed that LC-MS is known to be a relatively poorly sensitive technique allowing the detection of only abundantly expressed proteins. Accordingly, only 337 proteins constantly reached the threshold of detection in the analyzed samples, and paired comparisons showed that 10 proteins exhibited differential expression with p-values $<0.05$ (Data Supplement, Table S2). However, fold changes were relatively low $(<1.5)$, and statistical significance was not confirmed when p-values were adjusted with the Benjamini-Hochberg procedure. We nevertheless combined these results with a manual curation of the literature to identify candidate molecules which would be worth assessing with more sensitive techniques. Among the 10 identified candidate molecules, only superoxide dismutase 2 (SOD2) was 
previously shown to be regulated by NaHS. SOD2 is an antioxidant enzyme which decreases the level of ROS (reactive oxygen species), thus participating in cellular defense against oxidative stress. On this basis, we thus performed an ELISA measurement of SOD2 on cell extracts derived from NaHS-treated or control epidermal cell sheets and observed that NaHS induced a nearly $100 \%$ increase in SOD2 amounts in NaHS-treated epidermal cell sheets $(p<0.05)$ (Data Supplement, Figure S4). To further assess the links between NaHS and oxidative stress, we then performed a complementary bioinformatics analysis based on a survey of the comparative Toxocogenomics database (CTD) [13]. This approach allowed us to retrieve a list of 504 genes (Data Supplement, Table S3), which, in human cells, were previously reported to be modulated by hydrogen-sulfide-containing compounds. Confirming our proteomics data on SOD2, the highest functional enrichment retrieved from this list was obtained with genes annotated with the GO term "response to reactive oxygen species" (Table 1).

Table 1. Enrichment analysis of genes targeted by hydrogen-sulfide-containing compounds. The whole list of genes targeted by hydrogen-sulfide-containing compounds according to the CTD database [13] was submitted to an enrichment analysis. Enrichment in genes annotated with GO (gene ontology) terms of the "biological process" category was assessed using the enrichment analysis platform Enrichr [14]. To filter out GO terms corresponding to poorly specific biological functions, only GO terms annotating less than 100 genes were taken into account. Adjusted p-values provided by the Enrichr webtool were calculated with a modified Fisher exact test [14].

\begin{tabular}{lc}
\hline \multicolumn{1}{c}{ GO Term } & Adjusted $\boldsymbol{p}$-Value \\
\hline response to reactive oxygen species & $5.79 \times 10^{-19}$ \\
extrinsic apoptotic signaling pathway & $9.14 \times 10^{-18}$ \\
activation of cysteine-type endopeptidase activity involved in & $3.08 \times 10^{-17}$ \\
apoptotic process & $6.10 \times 10^{-17}$ \\
cellular response to reactive oxygen species & $7.22 \times 10^{-16}$ \\
glutathione metabolic process & $2.05 \times 10^{-15}$ \\
negative regulation of extrinsic apoptotic signaling pathway & $1.00 \times 10^{-14}$ \\
cellular response to mechanical stimulus & $2.73 \times 10^{-13}$ \\
I-kappaB kinase/NF-kappaB signaling & $2.73 \times 10^{-13}$ \\
interleukin-1-mediated signaling pathway & $3.46 \times 10^{-13}$ \\
toll-like receptor signaling pathway & \\
\hline
\end{tabular}

\subsection{NaHS Exerts Specific Effects on the RNA Profile of Cultured Human Keratinocytes}

We then performed an RNA-seq analysis to assess the genomic impact of $0.25 \mathrm{mM} \mathrm{NaHS}$ on human epidermal cell sheets. While 12.000 to 14.000 transcripts were detected in each sample, paired comparisons allowed identifying only 265 protein-coding differentially expressed genes with a fold change $>1.5$ and an adjusted $p$-value $<0.05$ (Data Supplement, Table S4). Among these 265 genes, 122 were up-regulated and 143 were down-regulated by NaHS treatment. While such lists were not enriched in genes signing specific molecular pathways according to the enrichment analysis platform Enrichr, 11 of the identified genes (Table 2) belonged to the list of 504 hydrogen sulfide target genes we retrieved from the CTD database. These notably comprised the oxidative stress response genes NQO1 (NAD(P)H Quinone Dehydrogenase 1) [15] and CUL3 (Culin 3) [16], the chemokine CXCL2 (C-X-C Motif Chemokine Ligand 2) [17-20] and the inflammasome component CASP1 (Caspase-1), which enables the maturation of IL-1 $\beta$ (Interleukin-1 $\beta$ ) and IL-18 (Interleukin-18) [21,22]. 
Table 2. List of NaHS-modulated keratinocyte genes previously shown to be targeted by sulfide-containing compounds. The list of genes identified as being modulated by NaHS in cultured epidermal cell sheets was crossed with the list of genes previously shown to be targeted by hydrogen sulfide-containing compounds according to the CTD database [13].

\begin{tabular}{ll}
\hline Gene Symbol & Gene Name \\
\hline Up-regulated genes & \\
\hline CASP1 & Caspase-1 \\
CAST & Calpastatin \\
CUL3 & Cullin 3 \\
CXCL2 & C-X-C motif chemokine ligand 2 \\
GDF15 & Growth differentiation factor 15 \\
NQO1 & NAD $P$ H H quinone dehydrogenase 1 \\
SLC3A2 & Solute carrier family 3 member 2 \\
UGT1A6 & UDP glucuronosyltransferase family 1 member A6 \\
\hline Down-regulated genes & \\
\hline CAMKK2 & Calcium/calmodulin dependent protein kinase kinase 2 \\
HOMER3 & Homer scaffold protein 3 \\
PTK2 & Protein tyrosine kinase 2 \\
\hline
\end{tabular}

\subsection{NaHS Modifies the Secretary Profile of Cultured Human Keratinocytes}

The results we obtained by RNA-seq analysis prompted us to investigate, at the protein level, the impact of $\mathrm{NaHS}$ on the secretion of specific components of the cytokine/chemokine inflammatory response. Besides CXCL2, IL-1 beta (IL-1 $\beta$ ) and IL-18, we focused our analysis on IL-8 (interleukin-8) and VEGF (vascular endothelial growth factor), two cytokines highly expressed by human keratinocytes under basal conditions [23-26]. We observed that NaHS, when applied at the concentration of $0.25 \mathrm{mM}$, induced a statistically significant increase in IL-1 $\beta$, IL-18, IL-8 and CXCL2 (Figure 3). However, a significant dose-dependent effect of NaHS was demonstrated only for the synthesis of IL-8 (Figure 3e) and CXCL2 (Figure 3a). Moreover, as compared to IL-18 (Figure 3c) and IL-1 $\beta$ (Figure 3b), the stimulating impact of NaHS was far more pronounced on IL-8 (maximal increase: 160\%) and CXCL2 (maximal increase: $90 \%$ ). Indeed, NaHS at a concentration of $0.25 \mathrm{mM}$ stimulated IL-8 secretion at similar levels to the prototypical pro-inflammatory cytokine TNF- $\alpha$ (tumor necrosis factor alpha) $[27,28]$ (Figure 3f). In addition, NaHS and TNF- $\alpha$ exerted synergistic stimulating effects on the synthesis of IL-8 (Figure 3f). Such findings remained unchanged when taking into account the impact of NaHS on the growth of epidermal cell sheets (Data Supplement, Figure S5). In contrast with the impact of NaHS on IL-8 secretion, NaHS induced an only limited increase in IL-1 $\beta$ synthesis. Of note, such an effect was not dose-dependent and was exclusively observed for a concentration of $0.25 \mathrm{mM}$ NaHS. Moreover, maximum mean values measured for IL- $1 \beta$ remained below $8 \mathrm{pg} / \mathrm{mL}$, compared to more than $6000 \mathrm{pg} / \mathrm{mL}$ for IL-8, nearly $1000 \mathrm{pg} / \mathrm{mL}$ for IL-18 and more than $60 \mathrm{pg} / \mathrm{mL}$ for CXCL2 (Data Supplement, Figure S6). Finally, NaHS had no measurable effect on the synthesis of VEGF (Figure 3d), a molecule sharing functional properties with IL-8 with regard to its pro-angiogenic effects. Altogether, these data demonstrate that NaHS modifies, in a specific manner, the chemokine/cytokine secretome of cultured human keratinocytes. 
a

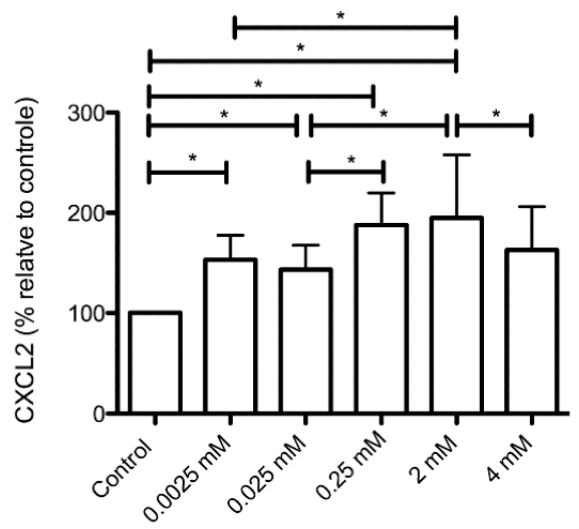

c

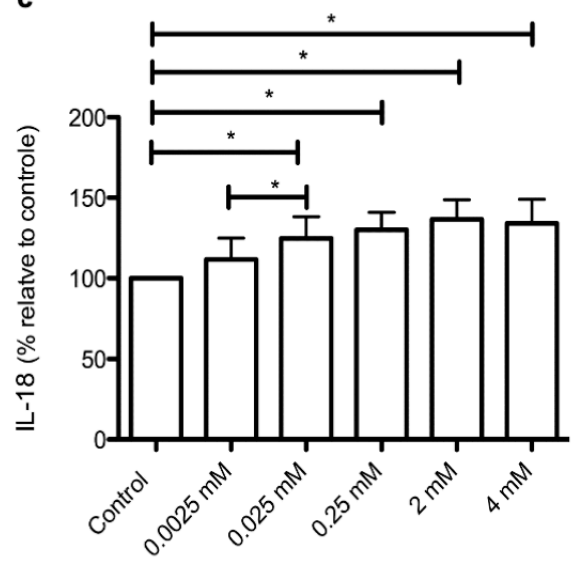

e

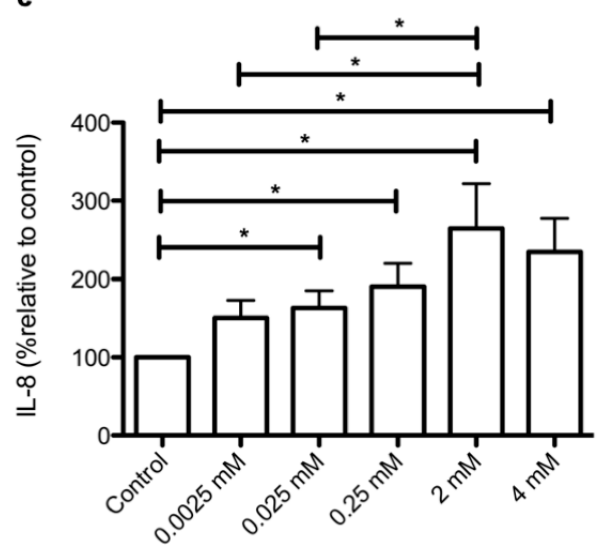

b

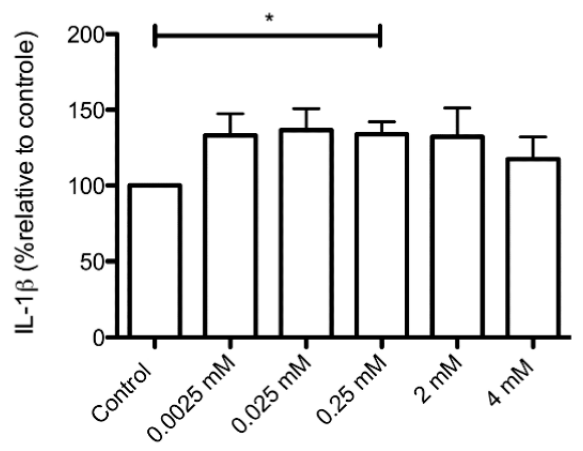

d

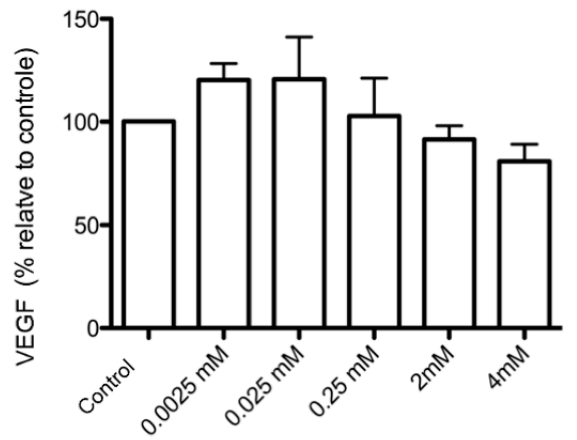

$\mathbf{f}$

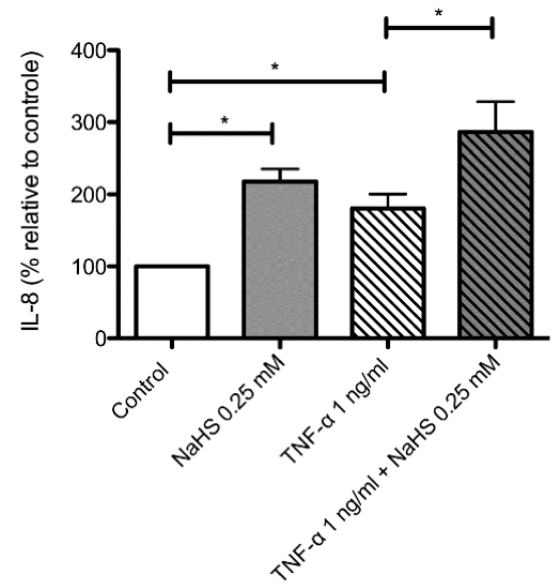

Figure 3. NaHS treatment modifies the cytokine/chemokine secretion profile of human epidermal cell sheets. Human epidermal cell sheets were cultured under control conditions or stimulated with NaHS at $0.0025,0.025,0.25,2$, or $4 \mathrm{mM}$, alone or in combination with TNF- $\alpha(1 \mathrm{ng} / \mathrm{mL}$ Cell supernatants were then recovered $24 \mathrm{~h}$ after stimulation and the cytokines CXCL2 (a), IL-1 $\beta$ (b), IL-18 (c), VEGF (d) and IL-8 (e-f) were measured by ELISA. Results are expressed as percentages relative to control measures observed in the absence of NaHS and/or TNF- $\alpha$ stimulation. Experiments were performed on epidermal cell sheets obtained from at least five distinct donors. The statistical significance of paired comparisons was assessed with the Wilcoxon test. *: $p<0.05$. 
2.6. Distinct Molecular Pathways Mediate the Stimulating Effects of NaHS on the Synthesis of IL-1 $\beta$ and IL-18 by Cultured Human Keratinocytes

To start getting insights into the molecular pathways involved in NaHS-induced alterations of the secretome of cultured human keratinocytes, we assessed whether a pharmacological inhibition of human caspase- 1 could block, at least partially, the stimulating effects exerted by NaHS on IL-1 $\beta$ and IL-18. We observed that, as expected, the stimulating effect of NaHS on IL-18 was significantly dampened in the presence of the caspase- 1 inhibitor Z-WHED-FMK (Figure 4a). In contrast, this was not observed regarding IL- $1 \beta$ synthesis (Figure $4 b$ ). It should be noticed that such a negative result might be explained by two combined parameters: i) the relatively low amplitude of the stimulating impact of NaHS on IL- $1 \beta$ secretion and ii) the fact that dimethysulfoxide (DMSO), used as a vehicle for the caspase-1 inhibitor Z-WHED-FMK, has itself exhibited a slight stimulating effect on IL-1 $\beta$ secretion. Finally, a western blot analysis showed that NaHS increased the levels of intracytoplasmic IL-1 $\beta$ proform (Figure $4 \mathrm{c}$ ), indicating that mechanisms complementing the caspase-1/inflammasome pathway may support the pro-inflammatory effects exerted by NaHS on cultured human keratinocytes.
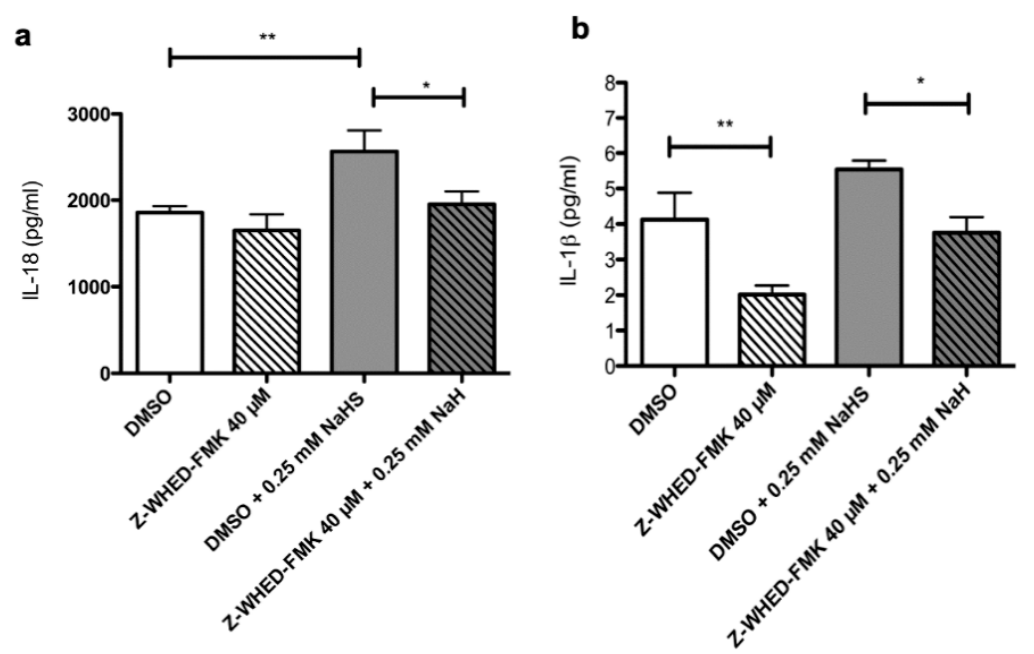

c
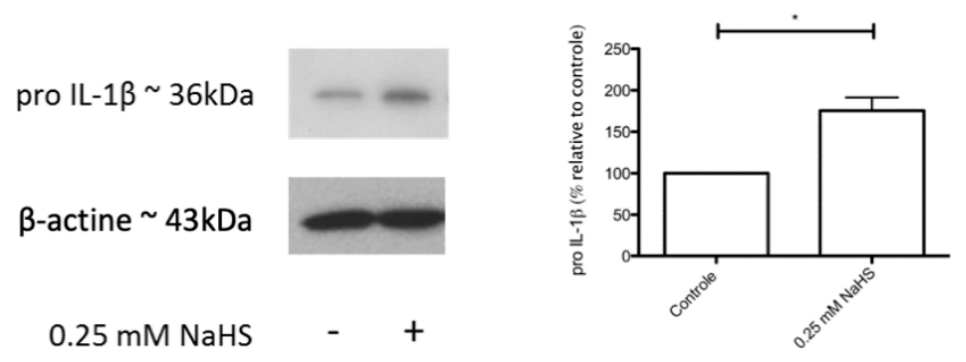

Figure 4. Role of the caspase-1 inflammasome pathway in NaHS-induced synthesis of IL-18 and IL-1 $\beta$. Human epidermal cell sheets were stimulated with NaHS at $0.25 \mathrm{mM}$ in the presence of either the caspase-1 inhibitor Z-WHED-FMK $40 \mu \mathrm{M}$ diluted in DMSO or DMSO alone (a,b). Cell supernatants were then recovered $24 \mathrm{~h}$ after stimulation and the cytokines IL-18 (a) and IL-1 $\beta$ (b) were measured by ELISA. In other experiments, the amount of IL- $1 \beta$ pro-form was measured by western blotting on protein extracts obtained from control or NaHS-treated human epidermal cell sheets (c). Experiments were performed three to five times on human epidermal cell sheets derived from one donor. Statistical significance of unpaired comparisons was assessed with the Mann and Whitney test.*: $p<0.05$; $* *: p<0.01$.

\section{Discussion}

Most of the results presented in this paper were obtained with a concentration of $0.25 \mathrm{mM} \mathrm{NaHS}$, i.e., $14 \mathrm{mg} / \mathrm{L}$ NaHS. Since each NaHS molecule generates one $\mathrm{H}_{2} \mathrm{~S}$ molecule, the expected concentration 
of $\mathrm{H}_{2} \mathrm{~S}$ corresponding to $0.25 \mathrm{mM} \mathrm{NaHS}$ is likely to stay in the concentration ranges previously measured in sulfur-rich spa waters, i.e., 0.5 to $20 \mathrm{mg} / \mathrm{L}$ [29]. We also demonstrated that a single stimulation with $\mathrm{NaHS}$ was sufficient to induce the subsequent accumulation of $\mathrm{H}_{2} \mathrm{~S}$ in the cytoplasm of cultured keratinocytes. These observations thus support the relevance of our experimental setting to study the molecular impact of sulfur-rich spa waters on human skin cells.

It should be noted that, among cells of the keratinocyte lineage, only keratinocyte stem cells and progenitors are endowed with the ability to proliferate under physiological conditions. Nevertheless, to our knowledge, the few works reporting on the effects of NaHS on the proliferation of human keratinocytes were performed exclusively on transformed or cancerous keratinocyte cell lines $[6,8,10]$. Using two distinct experimental settings, i.e., clonogenic cultures of keratinocytes and cultures of epidermal cell sheets, we found that NaHS hampered the growth of keratinocyte progenitors and stem cells. These findings contradict previous results obtained with keratinocyte cell lines $[6,8]$ and provide a possible explanation for the reported beneficial effects exerted by sulfur-rich spa waters in patients suffering from psoriasis, a keratinocyte hyperproliferative skin disease.

The present paper is also the first work reporting on a global mapping, at both the mRNA and protein levels, of the molecular effects exerted by NaHS on cultured human keratinocytes. Our data show that human keratinocytes exposed to NaHS engage an oxidative stress response involving SOD2, NQO1 and CUL3. We also report here that the whole list of currently known targets of sulfide-rich compounds is highly significantly enriched in antioxidant stress response genes. Accordingly, in other models and cell types, NaHS was similarly found to induce an oxidative stress response via the up-regulation of SOD1, SOD2, CAT (Catalase) and/or GPX (glutathione persoxydase 1) [30-32]. More specifically, previous reports demonstrated in non-skin cells that the NaHS-induced up-regulation of NQO1 and SOD2 mRNAs $[33,34]$ was mediated by the transcription factor NFEL2 (nuclear factor erythroid 2 like 2, also known as NRF2), a key orchestrator of the genomic oxidative stress response [35-37]. In this view, based on the well-established role of cullin-3 as a promoter of NRF2 degradation [34,38,39], the NaHS-induced up-regulation of CUL3 mRNA levels in human keratinocytes might reflect a negative feedback loop aimed at terminating the oxidative stress response. In any case, the primary molecular mechanisms linking $\mathrm{H}_{2} \mathrm{~S}$ to oxidative stress remain poorly understood. Of note, any intracytoplasmic elevation of $\mathrm{H}_{2} \mathrm{~S}$ levels results in the generation of reactive sulfur species (RSS), which, just as reactive oxygen species (ROS), trigger an anti-oxidative stress response [40]. In a rather provocative view, a recent paper proposed that in archaic forms of life, coping with a sulfur-rich environment was the primary function of genes which are now devoted to protect cells from oxidative stress [41].

Besides oxidative-stress-related molecules, we also found that, in epidermal cell sheets, NaHS specifically promoted the secretion of IL-8 and CXCL2, two cytokines/chemokines constitutively expressed by keratinocytes $[25,26,42]$ and involved in both skin inflammatory responses $[17,19]$ and skin repair $[43,44]$. In contrast, NaHS did not promote or only modestly promoted the synthesis of molecules that are frequently up-regulated under skin inflammatory conditions, namely VEGF and IL-1 $\beta$. Overall, the impact of NaHS on the secretory profile of human keratinocytes is specific and finely tuned and appears to involve multiple mechanisms operating at the transcriptional, translational and, possibly, post-translational levels.

Our work provides experimental evidence that $\mathrm{H}_{2} \mathrm{~S}$ contained in sulfur-rich spa waters is a bio-active component able to modify the immunological status of non-diseased human keratinocytes. Further studies are needed to establish causal links between the above-identified biological effects and the previously reported medical benefits afforded by sulfur-rich spa waters in conditions such as psoriasis, eczema or wound healing [1-4]. In particular, it would be interesting to assess the effects of $\mathrm{NaHS}$ on keratinocytes derived from psoriatic lesions. 


\section{Materials and Methods}

\subsection{Ethical Statement}

Samples were anonymized, and written informed consent was obtained in accordance with the ethical guidelines of Lyon University Hospital (Hospices Civils de Lyon) and the principles of the Declaration of Helsinki. All the samples used in this study belong to a collection of human skin samples declared to the French research ministry (Declaration no. DC-2008-162), delivered to the Bank of Tissues and Cells of the Hospices Civils de Lyon.

\subsection{Generation of Cultured Human Epidermal Sheets}

Normal human epidermal keratinocyte were grown on a feeder layer of irradiated human fibroblasts as previously described $[45,46]$ in keratinocyte culture medium (KCM). See the Supplementary Data for further details. When needed, cells were harvested with trypsin-EDTA 0.05\% (Thermo Fisher Scientific, Waltham, MA, USA) and collected for analysis.

\subsection{NaHS}

For each experiment, a fresh solution of 0.25 M NaHS (Sigma-Aldrich, St. Louis, MO, USA) dissolved in PBS was prepared and used as a stock solution to perform ad-hoc primary dilution in DMEM supplemented with $0.1 \%$ FCS. Depending on the desired final concentrations, secondary dilutions were then performed in cell culture medium.

\subsection{Measurements of $\mathrm{H}_{2} \mathrm{~S}$ in Culture Supernatants}

$\mathrm{H}_{2} \mathrm{~S}$ concentrations were measured in culture medium as previously described $[47,48]$ with slight modifications. Briefly, supernatants were collected at different time points (0-10-20-30-60 min-4 h-24 h) following the addition of $0.25 \mathrm{mM}$ NaHS to the cell culture medium. A quantity of $500 \mu \mathrm{L}$ of harvested supernatant was then mixed with $250 \mu \mathrm{L}$ of zinc acetate $(1 \% w / v)$, and $133 \mu \mathrm{L}$ of $N$,N-dimedthyl-p-phenulenediamine sulfate $(20 \mathrm{mM})$ in $7.2 \mathrm{M} \mathrm{HCl}$ was then added followed by $133 \mu \mathrm{L}$ of $\mathrm{FeCl}_{3}(30 \mathrm{mM})$ in $1.2 \mathrm{M} \mathrm{HCl}$ and $250 \mu \mathrm{L}$ of trichloroacetic acid $(10 \%, w / v)$. Within 15 min thereafter, absorbance was measured at $670 \mathrm{~nm}$. In parallel, a calibration curve was obtained from the analysis of defined $\mathrm{H}_{2} \mathrm{~S}$ concentrations (5-20-50-100-250 $\mu \mathrm{M}$ ).

\subsection{Fluorescence-Based Detection of Intracellular $\mathrm{H}_{2} \mathrm{~S}$}

Keratinocytes were cultured until sub-confluence on cover glasses in a 24-well plate. NaHS ( 0.25 or $2 \mathrm{mM})$ and $\mathrm{H}_{2} \mathrm{~S}$ fluorescent probes $\left(100 \mu \mathrm{M}, \mathrm{P} 3\right.$, Sigma) were co-incubated for $1 \mathrm{~h}$ at $37^{\circ} \mathrm{C}$ and $5 \% \mathrm{CO}_{2}$. Cells were rinsed 3 times in PBS $1 \mathrm{X}$ and fixed in $4 \%$ formaldehyde. Cover glasses were then transferred on a slide. Detection of intracellular fluorescence was carried out on an Eclipse 50i microscope (Nikon, Champigny sur Marne, Val-de-Marne, France).

\subsection{Clonogenic Assay}

A keratinocyte clonogenic assay was performed as previously described following a procedure routinely used in our laboratory [49]. See the Supplementary Data for further information. Experiments were performed on cells derived from five independent donors and a total of 12 flasks per donor (6 treated and 6 untreated) were analyzed.

\subsection{RNA-seq and Proteomics Analyses}

Epidermal cell sheets were generated by culturing human keratinocytes for 12 days as described above. Epidermal cell sheets were then treated or not for $24 \mathrm{~h}$ with $0.25 \mathrm{mM}$ NaHS then lysed using a RLT lysis buffer (Qiagen, Hilden, Germany) for RNA-seq analyses or mechanically detached using a cell scraper for proteomics analyses. RNA-seq and proteomics analyses were performed by the 
Lyon-1 university genomics platform ProfileXpert and the Lille university proteomics platform PRISM (Proteomics Inflammatory Response Mass Spectrometry, INSERM U1192), respectively, as previously described [50-53] and detailed in the Supplementary Data.

\subsection{Enzyme-Linked Immunosorbent Assay (ELISA)}

Standard procedures were applied and are detailed in the Supplementary Data.

\subsection{Western Blot Analysis}

Standard procedures were applied and are detailed in the Supplementary Data. To ensure that equal loading had been performed, membrane stainings with amido black were assessed as previously described [54]. Alternatively, membranes were incubated with an antibody against $\beta$-actin (1:2000, sc-47778, Clone C4, Santa Cruz Biotechnology, Inc, Heidelberg, Germany).

\subsection{Statistical Analysis}

Quantitative data obtained by ELISA or western blotting were generated from at least 5 independent experiments in which NaHS-stimulated cells were compared to control untreated cells. Statistical significance was calculated using the paired Wilcoxon test. In some experiments, the analyzed epidermal cell sheets were all generated from the same donor, and a Mann and Whitney test was thus used. To identify differentially expressed genes or proteins in RNA-seq and proteomics experiments, respectively, paired Student's $t$-tests were performed, and adjusted p-values were then calculated using the Benjamini-Hochberg procedure. All statistical analyses were performed using the software GraphPad Prism 4 (GraphPad Software Inc., La Jolla, CA, USA). Statistically significant differences in figures are indicated by asterisks as follows: ${ }^{*} p<0.05,{ }^{* *} p<0.001,{ }^{* * *} p<0.0001$.

\subsection{Data Availability}

The mass spectrometry proteomics data have been deposited to the ProteomeXchange Consortium via the PRIDE partner repository (https://www.ebi.ac.uk/pride/archive/) with the dataset identifier PXD01824. The RNA-seq data have been deposited on the GEO repository with the identifier GSE148985.

Supplementary Materials: Supplementary materials can be found at http://www.mdpi.com/1422-0067/21/13/4648/s1. Figure S1. NaHS induces the intracytoplasmic accumulation of H2S in keratinocyte. Figure S2. Representative flow cytometry data obtained on dissociated cells derived from cultured human epithelial cell sheets (Kera) vs irradiated fibroblasts (Fibros) used as a feeder layer for epidermal cell sheets. Figure S3. Impact of NaHS on the cell viability of cultured human keratinocyte. Figure S4. NaHS stimulates the synthesis of SOD2 by human epidermal cell sheets. Figure S5. NaHS stimulates the synthesis of IL-8 by human epidermal cell sheets. Figure S6. NaHS treatment modifies the cytokine/chemokine profile of human epidermal cell sheets. Table S1. Mean values obtained from the analysis of dissociated epidermal cell sheets $(n=44)$ for CD49f, CD90 and HMB45. Table S2. List of proteins detected by liquid chromatography/mass spectrometry as being modulated by NaHS in human epidermal cell sheets. Table S3. List of genes targeted by hydrogen sulfide-containing compounds according to the CTD database (only protein-coding genes were retained). Table S4. List of genes displaying significant differential expression in NaHS-treated vs control epidermal cell sheets.

Author Contributions: O.G.-A.: conceptualization, investigation, visualization, data curation and writing (original draft preparation); M.G.: investigation; J.-P.G.; investigation and data curation; M.S.: data curation, resources, and writing (review and editing); N.L.: conceptualization, supervision, funding acquisition and writing (review and editing); L.M.: conceptualization, supervision, funding acquisition and writing (review and editing); C.A.: conceptualization, data curation, supervision, funding acquisition and writing (original draft preparation); S.N.: conceptualization, data curation, supervision, funding acquisition and writing (original draft preparation). All authors have read and agreed to the published version of the manuscript.

Funding: This research was funded by a grant (to SN and CA) and a doctoral scholarship (to OG) from the French association for research on spa waters (AFRETH: "Association Française pour la Recherche Thermale").

Acknowledgments: This research was also supported by the "Ministère de L'Education Nationale, L'Enseignement Supérieur et de la Recherche", by INSERM, Hospices Civils de Lyon, CHRU Lille, University Claude Bernard Lyon-1 and University of Lille.

Conflicts of Interest: Laurent Misery is a consultant for Avène, Uriage and La Roche-Posay. 


\section{Abbreviations}

$\begin{array}{ll}\text { NAHS } & \text { Sodium hydrosulfide } \\ \mathrm{H}_{2} \mathrm{~S} & \text { Hydrogen sulfide } \\ \mathrm{IL} & \text { Interleukin }\end{array}$

\section{References}

1. Carbajo, J.M.; Maraver, F. Sulphurous Mineral Waters: New Applications for Health. Evid.-Based Complement. Altern. Med. 2017, 2017,1-11. [CrossRef]

2. Gianfaldoni, S.; Tchernev, G.; Wollina, U.; Roccia, M.G.; Fioranelli, M.; Gianfaldoni, R.; Lotti, T. History of the Baths and Thermal Medicine. Open Access Maced. J. Med. Sci. 2017, 5, 566-568. [CrossRef]

3. Huang, A.; Seité, S.; Adar, T. The use of balneotherapy in dermatology. Clin. Dermatol. 2018, 36, 363-368. [CrossRef]

4. Matz, H.; Orion, E.; Wolf, R. Balneotherapy in dermatology. Dermatol. Ther. 2003, 16, 132-140. [CrossRef] [PubMed]

5. Davinelli, S.; Bassetto, F.; Vitale, M.; Scapagnini, G. Chapter 10-Thermal Waters and the Hormetic Effects of Hydrogen Sulfide on Inflammatory Arthritis and Wound Healing. In The Science of Hormesis in Health and Longevity; Academic Press: Cambridge, MA, USA, 2019; pp. 121-126.

6. Xie, X.; Dai, H.; Zhuang, B.; Chai, L.; Xie, Y.; Li, Y. Exogenous hydrogen sulfide promotes cell proliferation and differentiation by modulating autophagy in human keratinocytes. Biochem. Biophys. Res. Commun. 2016, 472, 437-443. [CrossRef]

7. Mirandola, P.; Gobbi, G.; Micheloni, C.; Vaccarezza, M.; Di Marcantonio, D.; Ruscitti, F.; de Panfilis, G.; Vitale, M. Hydrogen sulfide inhibits IL-8 expression in human keratinocytes via MAP kinase signaling. Lab. Investig. 2011, 91, 1188-1194. [CrossRef]

8. Gobbi, G.; Ricci, F.; Malinverno, C.; Carubbi, C.; Pambianco, M.; de Panfilis, G.; Vitale, M.; Mirandola, P. Hydrogen sulfide impairs keratinocyte cell growth and adhesion inhibiting mitogen-activated protein kinase signaling. Lab. Investig. 2009, 89, 994-1006. [CrossRef] [PubMed]

9. Yang, C.; Yang, Z.; Zhang, M.; Dong, Q.; Wang, X.; Lan, A.; Zeng, F.; Chen, P.; Wang, C.; Feng, J. Hydrogen sulfide protects against chemical hypoxia-induced cytotoxicity and inflammation in HaCaT cells through inhibition of ROS/NF-kB/COX-2 pathway. PLoS ONE 2011, 6, e21971. [CrossRef]

10. Merighi, S.; Gessi, S.; Varani, K.; Fazzi, D.; Borea, P.A. Hydrogen sulfide modulates the release of nitric oxide and VEGF in human keratinocytes. Pharmacol. Res. 2012, 66, 428-436. [CrossRef] [PubMed]

11. Li, A.; Simmons, P.J.; Kaur, P. Identification and isolation of candidate human keratinocyte stem cells based on cell surface phenotype. Proc. Natl. Acad. Sci. USA 1998, 95, 3902-3907. [CrossRef] [PubMed]

12. Krebsbach, P.H.; Villa-Diaz, L.G. The Role of Integrin $\alpha 6$ (CD49f) in Stem Cells: More than a Conserved Biomarker. Stem Cells Dev. 2017, 26, 1090-1099. [CrossRef] [PubMed]

13. Davis, A.P.; Grondin, C.J.; Johnson, R.J.; Sciaky, D.; McMorran, R.; Wiegers, J.; Wiegers, T.C.; Mattingly, C.J. The Comparative Toxicogenomics Database: Update 2019. Nucleic Acids Res. 2019, 47, D948-D954. [CrossRef] [PubMed]

14. Kuleshov, M.V.; Jones, M.R.; Rouillard, A.D.; Fernandez, N.F.; Duan, Q.; Wang, Z.; Koplev, S.; Jenkins, S.L.; Jagodnik, K.M.; Lachmann, A.; et al. Enrichr: A comprehensive gene set enrichment analysis web server 2016 update. Nucleic Acids Res. 2016, 44, W90-W97. [CrossRef] [PubMed]

15. Ross, D.; Siegel, D. NQO1 in protection against oxidative stress. Curr. Opin. Toxicol. 2018, 7, 67-72. [CrossRef]

16. Kobayashi, A.; Kang, M.-I.; Okawa, H.; Ohtsuji, M.; Zenke, Y.; Chiba, T.; Igarashi, K.; Yamamoto, M. Oxidative Stress Sensor Keap1 Functions as an Adaptor for Cul3-Based E3 Ligase to Regulate Proteasomal Degradation of Nrf2. Mol. Cell. Biol. 2004, 24, 7130-7139. [CrossRef]

17. Boro, M.; Balaji, K.N. CXCL1 and CXCL2 Regulate NLRP3 Inflammasome Activation via G-Protein-Coupled Receptor CXCR2. J. Immunol. 2017, 199, 1660-1671. [CrossRef]

18. De Filippo, K.; Dudeck, A.; Hasenberg, M.; Nye, E.; van Rooijen, N.; Hartmann, K.; Gunzer, M.; Roers, A.; Hogg, N. Mast cell and macrophage chemokines CXCL1/CXCL2 control the early stage of neutrophil recruitment during tissue inflammation. Blood 2013, 121, 4930-4937. [CrossRef] 
19. Rajarathnam, K.; Schnoor, M.; Richardson, R.M.; Rajagopal, S. How do chemokines navigate neutrophils to the target site: Dissecting the structural mechanisms and signaling pathways. Cell. Signal. 2019, 54, 69-80. [CrossRef]

20. Rouault, C.; Pellegrinelli, V.; Schilch, R.; Cotillard, A.; Poitou, C.; Tordjman, J.; Sell, H.; Clément, K.; Lacasa, D. Roles of chemokine ligand-2 (CXCL2) and neutrophils in influencing endothelial cell function and inflammation of human adipose tissue. Endocrinology 2013, 154, 1069-1079. [CrossRef]

21. Guo, H.; Callaway, J.B.; Ting, J.P.-Y. Inflammasomes: Mechanism of action, role in disease, and therapeutics. Nat. Med. 2015, 21, 677-687. [CrossRef]

22. Lee, D.-J.; Du, F.; Chen, S.-W.; Nakasaki, M.; Rana, I.; Shih, V.F.S.; Hoffmann, A.; Jamora, C. Regulation and function of the caspase-1 in an inflammatory microenvironment. J. Investig. Dermatol. 2015, 135, 2012-2020. [CrossRef] [PubMed]

23. Kim, H.; Kang, J.S.; Lee, W.J. The Production IL-21 and VEGF in UVB-irradiated Human Keratinocyte Cell Line, HaCaT. Immune Netw. 2010, 10, 75-80. [CrossRef] [PubMed]

24. Viac, J.; Palacio, S.; Schmitt, D.; Claudy, A. Expression of vascular endothelial growth factor in normal epidermis, epithelial tumors and cultured keratinocytes. Arch. Dermatol. Res. 1997, 289, 158-163. [CrossRef] [PubMed]

25. Rennekampff, H.-O.; Hansbrough, J.F.; Kiessig, V.; Doré, C.; Sticherling, M.; Schröder, J.-M. Bioactive Interleukin-8 Is Expressed in Wounds and Enhances Wound Healing. J. Surg. Res. 2000, 93, 41-54. [CrossRef] [PubMed]

26. Sticherling, M.; Bornscheuer, E.; Schröder, J.M.; Christophers, E. Localization of neutrophil-activating peptide-1/interleukin-8-immunoreactivity in normal and psoriatic skin. J. Investig. Dermatol. 1991, 96, $26-30$. [CrossRef]

27. Bhattacharyya, S.; Dudeja, P.K.; Tobacman, J.K. Tumor Necrosis Factor $\alpha$-induced Inflammation Is Increased but Apoptosis Is Inhibited by Common Food Additive Carrageenan. J. Biol. Chem. 2010, 285, 39511-39522. [CrossRef]

28. Zhou, P.; Lu, S.; Luo, Y.; Wang, S.; Yang, K.; Zhai, Y.; Sun, G.; Sun, X. Attenuation of TNF- $\alpha$-Induced Inflammatory Injury in Endothelial Cells by Ginsenoside Rb1 via Inhibiting NF- $\kappa B$, JNK and p38 Signaling Pathways. Front. Pharmacol. 2017, 8, 464. [CrossRef]

29. Carubbi, C.; Gobbi, G.; Bucci, G.; Gesi, M.; Vitale, M.; Mirandola, P. Skin, Inflammation and Sulfurous Waters: What is Known, What is Believed, Skin, Inflammation and Sulfurous Waters: What is Known, What is Believed. Eur. J. Inflamm. 2013, 11, 591-599. [CrossRef]

30. Zhao, F.; Lei, F.; Yan, X.; Zhang, S.; Wang, W.; Zheng, Y. Protective Effects of Hydrogen Sulfide Against Cigarette Smoke Exposure-Induced Placental Oxidative Damage by Alleviating Redox Imbalance via Nrf2 Pathway in Rats. Cell. Physiol. Biochem. 2018, 48, 1815-1828. [CrossRef]

31. Liang, Y.; Zheng, P.; Li, S.; Li, K.; Xu, H. Nitrate reductase-dependent NO production is involved in H2S-induced nitrate stress tolerance in tomato via activation of antioxidant enzymes. Sci. Hortic. 2018, 229, 207-214. [CrossRef]

32. Wen, Y.-D.; Wang, H.; Kho, S.; Rinkiko, S.; Sheng, X.; Shen, H.-M.; Zhu, Y.-Z. Hydrogen Sulfide Protects HUVECs against Hydrogen Peroxide Induced Mitochondrial Dysfunction and Oxidative Stress. PLoS ONE 2013, 8, e53147. [CrossRef] [PubMed]

33. Glory, A.; Averill-Bates, D.A. The antioxidant transcription factor Nrf2 contributes to the protective effect of mild thermotolerance $\left(40^{\circ} \mathrm{C}\right)$ against heat shock-induced apoptosis. Free Radic. Biol. Med. 2016, 99, 485-497. [CrossRef] [PubMed]

34. Shen, J.; Rasmussen, M.; Dong, Q.-R.; Tepel, M.; Scholze, A. Expression of the NRF2 Target Gene NQO1 Is Enhanced in Mononuclear Cells in Human Chronic Kidney Disease. Oxid. Med. Cell. Longev. 2017, 2017, 9091879. [CrossRef] [PubMed]

35. Xie, Z.-Z.; Liu, Y.; Bian, J.-S. Hydrogen Sulfide and Cellular Redox Homeostasis. Oxid. Med. Cell. Longev. 2016, 2016, 6043038. [CrossRef]

36. Meng, W.; Pei, Z.; Feng, Y.; Zhao, J.; Chen, Y.; Shi, W.; Xu, Q.; Lin, F.; Sun, M.; Xiao, K. Neglected role of hydrogen sulfide in sulfur mustard poisoning: Keap1 S-sulfhydration and subsequent Nrf2 pathway activation. Sci. Rep. 2017, 7, 1-17. [CrossRef]

37. Corsello, T.; Komaravelli, N.; Casola, A. Role of Hydrogen Sulfide in NRF2- and Sirtuin-Dependent Maintenance of Cellular Redox Balance. Antioxidants (Basel) 2018, 7, 129. [CrossRef] 
38. Kaspar, J.W.; Jaiswal, A.K. An Autoregulatory Loop between Nrf2 and Cul3-Rbx1 Controls Their Cellular Abundance. J. Biol. Chem. 2010, 285, 21349-21358. [CrossRef]

39. Li, R.; Jia, Z.; Zhu, H. Regulation of Nrf2 Signaling. React. Oxyg. Species (Apex) 2019, 8, 312-322. [CrossRef]

40. Olson, K.R.; Gao, Y.; Arif, F.; Arora, K.; Patel, S.; DeLeon, E.R.; Sutton, T.R.; Feelisch, M.; Cortese-Krott, M.M.; Straub, K.D. Metabolism of hydrogen sulfide (H2S) and Production of Reactive Sulfur Species (RSS) by superoxide dismutase. Redox Biol. 2017, 15, 74-85. [CrossRef]

41. Olson, K.R.; Gao, Y. Effects of inhibiting antioxidant pathways on cellular hydrogen sulfide and polysulfide metabolism. Free Radic. Biol. Med. 2019, 135, 1-14. [CrossRef]

42. Olaru, F.; Jensen, L.E. Staphylococcus aureus stimulates neutrophil targeting chemokine expression in keratinocytes through an autocrine IL-1alpha signaling loop. J. Investig. Dermatol. 2010, 130, 1866-1876. [CrossRef] [PubMed]

43. Ridiandries, A.; Tan, J.T.M.; Bursill, C.A. The Role of Chemokines in Wound Healing. Int. J. Mol. Sci. 2018, 19, 3217. [CrossRef] [PubMed]

44. Gillitzer, R.; Goebeler, M. Chemokines in cutaneous wound healing. J. Leukoc. Biol. 2001, 69, 513-521. [PubMed]

45. Barrandon, Y.; Green, H. Three clonal types of keratinocyte with different capacities for multiplication. Proc. Natl. Acad. Sci. USA 1987, 84, 2302-2306. [CrossRef] [PubMed]

46. Black, A.F.; Bouez, C.; Perrier, E.; Schlotmann, K.; Chapuis, F.; Damour, O. Optimization and characterization of an engineered human skin equivalent. Tissue Eng. 2005, 11, 723-733. [CrossRef] [PubMed]

47. Zhu, Y.Z.; Wang, Z.J.; Ho, P.; Loke, Y.Y.; Zhu, Y.C.; Huang, S.H.; Tan, C.S.; Whiteman, M.; Lu, J.; Moore, P.K. Hydrogen sulfide and its possible roles in myocardial ischemia in experimental rats. J. Appl. Physiol. 2007, 102, 261-268. [CrossRef]

48. Li, L.; Bhatia, M.; Zhu, Y.Z.; Zhu, Y.C.; Ramnath, R.D.; Wang, Z.J.; Anuar, F.B.M.; Whiteman, M.; Salto-Tellez, M.; Moore, P.K. Hydrogen sulfide is a novel mediator of lipopolysaccharide-induced inflammation in the mouse. FASEB J. 2005, 19, 1196-1198. [CrossRef]

49. Jobeili, L.; Rousselle, P.; Béal, D.; Blouin, E.; Roussel, A.-M.; Damour, O.; Rachidi, W. Selenium preserves keratinocyte stemness and delays senescence by maintaining epidermal adhesion. Aging (Albany NY) 2017, 9, 2302-2315. [CrossRef]

50. Arab, T.; Raffo-Romero, A.; Van Camp, C.; Lemaire, Q.; Le Marrec-Croq, F.; Drago, F.; Aboulouard, S.; Slomianny, C.; Lacoste, A.-S.; Guigon, I.; et al. Proteomic characterisation of leech microglia extracellular vesicles (EVs): Comparison between differential ultracentrifugation and Optiprep ${ }^{\mathrm{TM}}$ density gradient isolation. J. Extracell. Vesicles 2019, 8, 1603048. [CrossRef]

51. Sinel, C.; Cacaci, M.; Meignen, P.; Guérin, F.; Davies, B.W.; Sanguinetti, M.; Giard, J.-C.; Cattoir, V. Subinhibitory Concentrations of Ciprofloxacin Enhance Antimicrobial Resistance and Pathogenicity of Enterococcus faecium. Antimicrob. Agents Chemother. 2017, 61, e02763-16. [CrossRef]

52. Cardon, T.; Hervé, F.; Delcourt, V.; Roucou, X.; Salzet, M.; Franck, J.; Fournier, I. Optimized Sample Preparation Workflow for Improved Identification of Ghost Proteins. Anal. Chem. 2020, 92, 1122-1129. [CrossRef] [PubMed]

53. Delloye-Bourgeois, C.; Bertin, L.; Thoinet, K.; Jarrosson, L.; Kindbeiter, K.; Buffet, T.; Tauszig-Delamasure, S.; Bozon, M.; Marabelle, A.; Combaret, V.; et al. Microenvironment-Driven Shift of Cohesion/Detachment Balance within Tumors Induces a Switch toward Metastasis in Neuroblastoma. Cancer Cell 2017, 32, 427-443.e8. [CrossRef] [PubMed]

54. Bringuier, P.-P.; Schalken, J.A.; Hervieu, V.; Giroldi, L.A. Involvement of orphan nuclear receptor COUP-TFII in cadherin-6 and cadherin-11 regulation: Implications in development and cancer. Mech. Dev. 2015, 136, 64-72. [CrossRef] [PubMed]

(C) 2020 by the authors. Licensee MDPI, Basel, Switzerland. This article is an open access article distributed under the terms and conditions of the Creative Commons Attribution (CC BY) license (http://creativecommons.org/licenses/by/4.0/). 